\title{
Advances in nuclear desalination
}

\author{
Braj Mohan Misra \\ Desalination Division, Bhabha Atomic Research Centre, \\ Trombay, Mumbai 400 085, India \\ E-mail: bmmisra@magnum.barc.ernet.in
}

\begin{abstract}
The Nuclear Desalination Demonstration Project (NDDP) at Kalpakkam aims to demonstrate the safe and economic production of good quality water by desalination of seawater comprising $4,500 \mathrm{~m}^{3} / \mathrm{d}$ Multi-Stage Flash (MSF) and $1,800 \mathrm{~m}^{3} / \mathrm{d}$ Reverse Osmosis (RO) plant. The design of the hybrid MSF-RO plant to be set up at an existing nuclear power station is presented. The MSF plant based on long tube design requires less energy. The effect on performance of the MSF plant due to higher seawater intake temperature is marginal. The preheat RO system part of the hybrid plant uses reject cooling seawater from the MSF plant. This allows lower pressure operation, resulting in energy saving. The two qualities of water produced are usable for the power station as well as for drinking purposes with appropriate blending. The post treatment is also simplified due to blending of the products from MSF and RO plants.
\end{abstract}

The hybrid plant has a number of advantages:

- $\quad$ Part of high purity desalted water produced from the MSF plant will be used for the makeup demineralised water requirement (after necessary polishing) for the power station.

- Blending of the product water from RO and MSF plants would provide requisite quality drinking water.

- The RO plant will continue to be operated to provide water for drinking purposes during the shut down of the power station.

Commissioning of the RO section is expected in 2002 and that of the MSF section in 2003. Useful design data are expected from the plant on the coupling of small and medium size reactors (SMR) based on PHWR. This will enable us to design a large size commercial plant up to $50,000 \mathrm{~m}^{3} / \mathrm{d}$ capacity. India will share the O\&M experience of NDDP to member states of the International Atomic Energy Agency (IAEA) when the plant is commissioned.

The development work for producing good quality water for power station from high salinity water utilizing low grade waste heat is presented. About 40 and $100 \mathrm{MWth}$ low temperature waste heat is available in the moderator systems of the 220 and 500 MWe PHWR respectively. A significant part of this waste heat can be utilized for seawater desalination for in-house consumption. The Low Temperature Evaporation (LTE) technology for producing low conductivity water from seawater has been demonstrated at BARC on $30 \mathrm{~m}^{3} / \mathrm{d}$ scale by using waste heat. This plant is being connected to the CIRUS reactor for demonstration of coupling to a nuclear research reactor. The product water from this plant after minor polishing will meet the make up water requirement of the research reactor.

Keywords: hybrid; MSF; RO; preheat; integrated system; combined posttreatment; waste heat. 
Reference to this paper should be made as follows: Misra, B.M. (2003) 'Advances in nuclear desalination', International Journal of Nuclear Desalination, Vol. 1, No. 1, pp. 19-29.

Biographical notes: Dr. B.M. Misra was a Research Associate at Harvard, UCLA, and Texas Tech. University after completing his Ph.D. in India.

Presently he is the Head of the Desalination Division in Bhabha Atomic Research Centre, Mumbai. He is the Ex-President of Indian Desalination Association, the Vice President of Indian Membrane Society, Member of International Desalination Association and Board of Director for IUPAC Commission on Soil \& Water Chemistry, Editorial Board International Journal of Nuclear Desalination and many Indian Scientific Societies.

His research interest include membrane desalination and industrial separation, thermal desalination processes for sea water desalting, Nuclear Desalination. He has 150 research publications and guided 22 M.Sc. and Ph.D. students.

\section{Introduction}

BARC has been engaged in R\&D on desalination since the 1970s. The desalination activities were part of a program of setting up a number of demonstration plants for the energy intensive processes such as desalination of seawater, electrolytic production of hydrogen, and electro-thermal production of phosphorus. These activities are currently termed by the IAEA as 'Non Electrical Application of Nuclear Energy'. Table 1 gives some of the pilot plants installed and operated successfully.

Table 1 Pilot plants installed and operated

\begin{tabular}{lc}
\hline Thermal & Year of commissioning \\
\hline $30 \mathrm{~m}^{3} / \mathrm{d}$ LTE plant, Trombay & 1985 \\
$425 \mathrm{~m}^{3} / \mathrm{d}$ MSF plant, Trombay & 1990 \\
II Membrane & \\
$50 \mathrm{~m}^{3} / \mathrm{d}$ RO industrial effluent treatment plant at RCF Mumbai & 1986 \\
$20 \mathrm{~m}^{3} / \mathrm{d}$ RO-DM at VECC, Kolkata for low conductivity water & 1994 \\
$100 \mathrm{~m}^{3} / \mathrm{d}$ SWRO plant at Trombay & 1999 \\
\hline
\end{tabular}

India has inadequate sources of fossil fuels and the costs are high. Design of our desalination plants therefore concerns energy saving. This is achievable via technological development, breakthrough technology and by process integration. In this context nuclear energy is also considered as one of the options both from long-term availability as well as the present substitute of scarce fossil fuels. The concept of a hybrid MSF-RO plant along with a few innovative features has been considered advantageous in many respects. Utilization of waste heat for low temperature evaporation is an attempt towards energy saving. The details of a combined MSF-RO Nuclear Desalination Demonstration plant at PHWR, Kalpakkam and a Low Temperature Evaporation unit at CIRUS research reactor, Trombay are presented in this article.

\section{$26,300 \mathrm{~m}^{3} / \mathrm{d}$ combined MSF-RO plant [1]}

The Indian Nuclear Desalination Demonstration Project (NDDP) was evolved with a view to demonstrating the feasibility of safe and cost effective production of potable 
water from seawater desalination utilizing a hybrid plant based on MSF and RO technologies coupled to an existing PHWR. The hybrid plant was considered in order to gain experience on both thermal and membrane technologies developed in the country and utilize the advantages of a hybrid plant, which are described below.

\subsection{Site aspects}

The nuclear desalination plant is located between the existing PHWR, MAPS and the proposed PFBR. The desalination plant utilizes power steam and seawater from MAPS. The location of the desalination plant at an existing nuclear reactor has resulted in many experiences not encountered in a desalination plant to be coupled to a new nuclear power plant.

- The steam tapping for NDDP could not be done in either back pressure or extraction mode from an LP turbine as it required modification in the station, which was not desirable. Steam is therefore taken from cold reheat lines after the HP turbines exhaust and employing adequate moisture separation.

- No additional seawater from the existing seawater intake for the station was available. As the site is known to have excessive sand movement, a new seawater intake was not considered suitable. The Kalpakkam site is also prone to excessive biofouling from raw seawater. It was therefore decided to utilize the process seawater coolant outfall as feed to the desalination plants. The condenser cooling seawater was not considered as it is at higher temperature than the process seawater outfall temperature. Further, the process seawater coolant is available even during the long shut down of the reactor.

- The coolant seawater from the MSF plant, which is disposed, otherwise is blended with some raw seawater to bring it to a temperature of $35-36^{\circ} \mathrm{C}$ to be used as feed to the SWRO plant. This would help operate the RO plant at a relatively lower pressure, however, with a slightly higher salinity of product. This is tolerable as the product water from the RO plant is blended with the product of the MSF plant having low TDS. The blending also simplifies the post-treatment and the combined product with appropriate LSI is obtained with minimal treatment.

\subsection{Details of hybrid MSF-RO plant}

Figure 1 shows the coupling scheme of the hybrid desalination plant with the nuclear power plant for utilizing seawater, steam and power.

\subsubsection{Seawater intake and steam source [2]}

The hybrid desalination plant requires around $2,000 \mathrm{~m}^{3} / \mathrm{h}$ seawater. Different alternatives for seawater intake were considered and evaluated. A bathymetric and morphological survey was carried out. The geology of the seabed was identified. Tests were carried out for the soil bearing capacity, erosion and depositional characteristics of the seabed. From the bathymetry and seabed soil characteristics, it is observed that the seabed primarily consists of silty sand. Morphological changes along the beach are very high with respect to seasonal changes. After detailed studies, it has been decided to use process 
Figure $16,300 \mathrm{~m}^{3} / \mathrm{d}$ MSF-RO desalination plant coupled to $170 \mathrm{MWe}$ PHWR

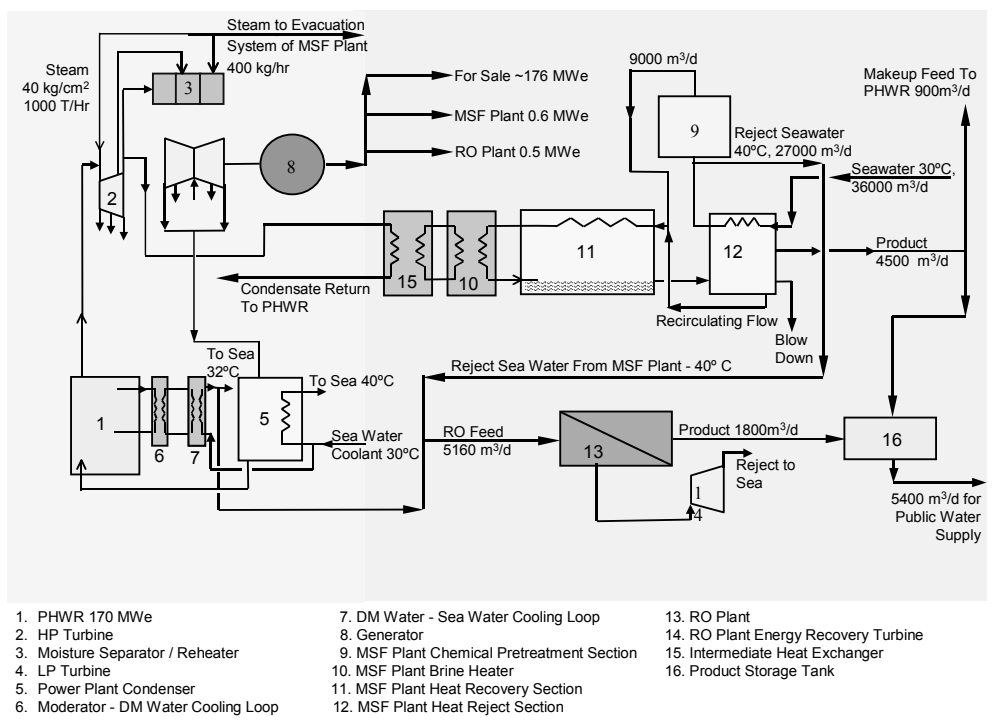

cooling water from the outfall seal pit of the power station as a source of seawater supply. The outfall seawater temperature varies from $26^{\circ} \mathrm{C}$ to $32^{\circ} \mathrm{C}$, which is about $4{ }^{\circ} \mathrm{C}$ higher than ambient temperature due to heat being rejected from the process cooling water system.

The variation in seawater temperature may have some effect on the performance of MSF. Experiments were carried out in our pilot plant to study the effect of seawater temperature and the temperature rise of seawater coolant in the heat reject section of the MSF. The results collected for seawater temperature varying from $30^{\circ} \mathrm{C}$ to $36^{\circ} \mathrm{C}$ are given in Table 2. The higher seawater temperature for the MSF plant leads to loss in production rate and GOR. Analysis has been carried out for operating the plant at lower reject seawater temperature by increasing the seawater flow rate in the heat reject section. This has been done to maintain lower seawater discharge temperature in case it is required due to environmental considerations. It is noted that the production of desalted water can be maintained or increased slightly within the design limits by increasing the coolant flow rate.

In order to avoid any chance of ingress of radioactivity (tritium) to the MSF process and product water, it was decided to incorporate an isolation heat exchanger between MAPS steam supply and the brine heater of MSF. The LP steam is tapped from the manholes in the cold reheat lines after HP turbine exhaust from both the nuclear reactors (MAPS I and II). The moisture is removed through a moisture separator. The steam is sent to an intermediate isolation heat exchanger to produce process steam for the brine heater of the MSF plant. Adequate provisions for monitoring and control have been incorporated for isolation of the steam supply in case of shut down of the power station or desalination plant. A small amount of HP steam is withdrawn and sent to the HP intermediate heat exchanger before reaching the ejectors. Figure 2 shows the flow details of both the isolation heat exchangers. The loss of steam pressure in both the IHX is due to a distance of $600 \mathrm{~m}$ between the reactor and the desalination plant. 
Table 2 Effect of seawater temperature and heat reject condenser coolant temperature rise on desalted water production

\begin{tabular}{|c|c|c|c|c|c|c|}
\hline \multirow{2}{*}{$\begin{array}{l}S . \\
\text { No. }\end{array}$} & \multicolumn{2}{|c|}{$\begin{array}{l}\text { Coolant } \\
\text { seawater } \\
\text { temperature } \\
\left({ }^{\circ} \mathrm{C}\right) \\
\end{array}$} & \multirow{2}{*}{$\begin{array}{c}\text { Coolant } \\
\text { temperature } \\
\text { rise } \\
\left({ }^{\circ} \mathrm{C}\right)\end{array}$} & \multirow{2}{*}{$\begin{array}{c}\text { Flashing brine } \\
\text { temperature entering } \\
\text { heat reject section } \\
\left({ }^{\circ} \mathrm{C}\right)\end{array}$} & \multirow{2}{*}{$\begin{array}{c}\text { Seawater } \\
\text { coolant flow } \\
\text { rate } \\
\left(\mathrm{m}^{3} / \mathrm{h}\right)\end{array}$} & \multirow{2}{*}{$\begin{array}{c}\text { Production } \\
\text { rate } \\
\left(\mathrm{m}^{3} / \mathrm{h}\right)\end{array}$} \\
\hline & In & Out & & & & \\
\hline 1 & 30 & 40 & 10 & 47.8 & 1160.9 & 187.88 \\
\hline 2 & 32 & 42 & 10 & 49.8 & 1160.9 & 183.76 \\
\hline 3 & 34 & 44 & 10 & 51.8 & 1160.9 & 179.63 \\
\hline 4 & 36 & 46 & 10 & 53.8 & 1160.9 & 175.47 \\
\hline 5 & 30 & 39 & 9 & 46.8 & 1289.91 & 189.93 \\
\hline 6 & 32 & 41 & 9 & 48.8 & 1289.91 & 185.85 \\
\hline 7 & 34 & 43 & 9 & 50.8 & 1289.91 & 181.69 \\
\hline 8 & 36 & 45 & 9 & 52.8 & 1289.91 & 177.56 \\
\hline 9 & 30 & 38 & 8 & 45.8 & 1451.15 & 191.97 \\
\hline 10 & 32 & 40 & 8 & 47.8 & 1451.15 & 187.87 \\
\hline 11 & 34 & 42 & 8 & 49.8 & 1451.15 & 183.77 \\
\hline 12 & 36 & 44 & 8 & 51.8 & 1451.15 & 179.63 \\
\hline 13 & 30 & 37 & 7 & 44.8 & 1658.46 & 194.0 \\
\hline 14 & 32 & 39 & 7 & 46.8 & 1658.46 & 190.0 \\
\hline 15 & 34 & 41 & 7 & 48.8 & 1658.46 & 185.85 \\
\hline 16 & 36 & 43 & 7 & 50.8 & 1658.46 & 171.71 \\
\hline
\end{tabular}

Figure 2 Flow details of isolation heat exchangers

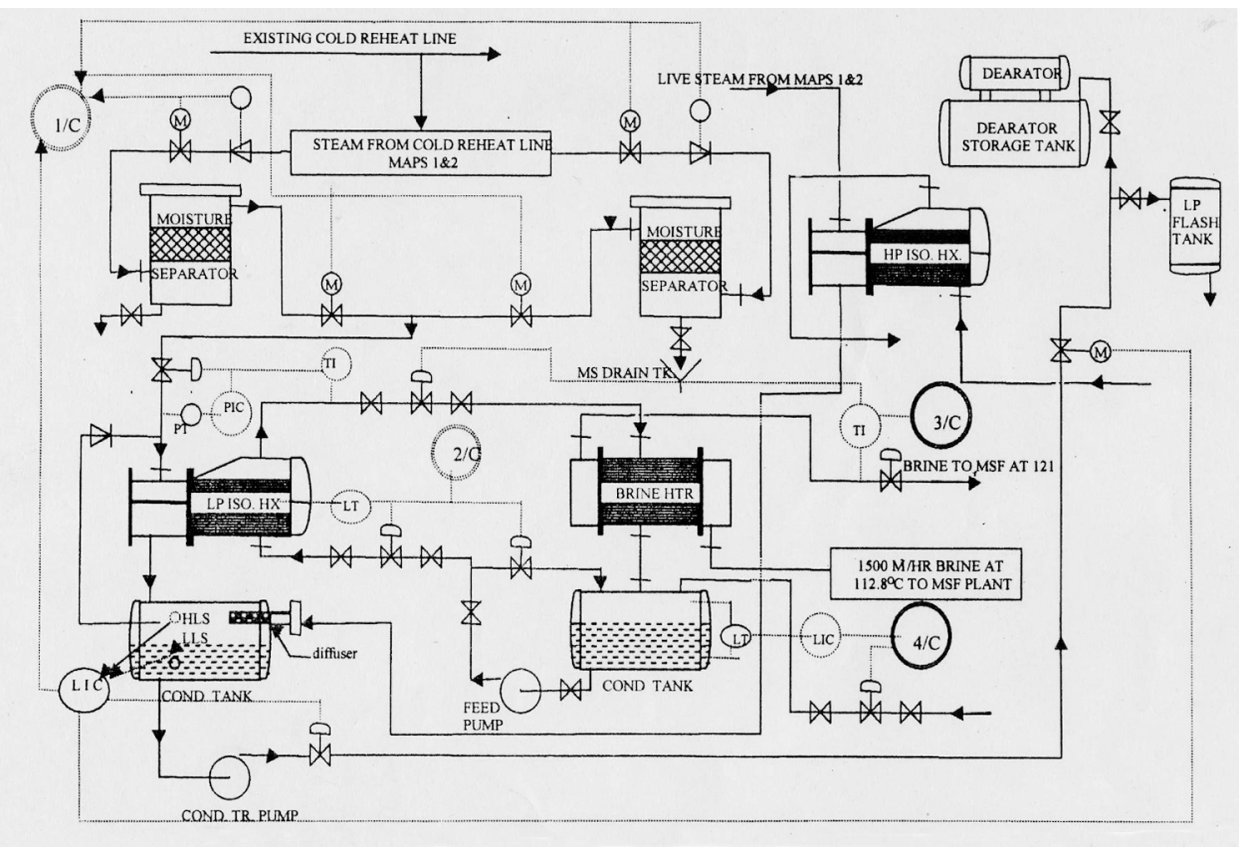




\subsection{2 $4,500 \mathrm{~m}^{3} / \mathrm{d}$ multistage flash (MSF) plant}

The MSF plant, a scale-up of our pilot plant, is based on a long tube design, recirculation type with acid dosing. It consists of nine recovery modules each of four flash stages and one recovery module of three flash stages. Maximum brine temperature is limited to $121^{\circ} \mathrm{C}$ to avert calcium sulphate scaling on cupronickel heat transfer tubes. The pumping power requirement is $2.5 \mathrm{~kW} \mathrm{~h} / \mathrm{m}^{3}$ of water produced. It will produce high quality product water from seawater. The salient features of the MSF plant are given in Table 3.

Table 3 Specifications of $4,500 \mathrm{~m}^{3} / \mathrm{d}$ MSF plant

\begin{tabular}{llc}
\hline 1 & Product water output & $187.5 \mathrm{~m}^{3} / \mathrm{h}$ \\
2 & Product water salt content & $<50 \mathrm{ppm}$ \\
3 & Sea water requirement & \\
& 3.1 Total (cooling) & $1544 \mathrm{~m}^{3} / \mathrm{h}$ \\
& 3.2 Make-up feed (Part of A) & $375 \mathrm{~m}^{3} / \mathrm{h}$ \\
4 & Brine temperature & \\
& $4.1 \quad$ Max. recirculation brine temperature & $121^{\circ} \mathrm{C}$ \\
& 4.2 Blow down temperature & $40^{\circ} \mathrm{C}$ \\
5 & Concentration ratio & 2 \\
6 & Steam consumption & $20.6 \mathrm{Te} / \mathrm{h}(2.8 \mathrm{bar})$ \\
& 6.1 Heating in the brine heater & $400.0 \mathrm{~kg} / \mathrm{h}(7 \mathrm{bar})$ \\
7 & 6.2 Steam jet ejectors & 9 \\
8 & Gain output ratio & $475 \mathrm{kWe}$ \\
\hline
\end{tabular}

In the long tube design the incoming brine flow path is parallel to the flashing brine. It is easier and less expensive to have a large number of flash stages in a long tube design than in a cross tube design. The long tube design has been chosen due to low capital cost and less pumping energy requirement The pretreatment scheme for the MSF plant involves acidification, vacuum de-aeration for control of $\mathrm{O}_{2} / \mathrm{CO}_{2}$ concentration, $\mathrm{pH}$ control by alkali neutralization followed by antifoam dosing.

\subsection{3 $1,800 \mathrm{~m}^{3} / \mathrm{d}$ reverse osmosis (RO) plant [3]}

Our RO plant design differs from the seawater RO plants set up internationally in a relatively lower pressure operation to save energy. The high temperature operation results in lowering the operational pressure to about $52 \mathrm{~kg} / \mathrm{cm}^{2}$. Slightly high TDS of RO permeate of 500-600 ppm is tolerated because this product water is blended with product water from MSF. The low pressure operation may also contribute to the long life of the membranes due to less possibility of compaction. The salient parameters of RO plant are given in Table 4. 
Table 4 Technical specifications of $1,800 \mathrm{~m}^{3} / \mathrm{d}$ SWRO desalination plant

\begin{tabular}{llc}
\hline 1 & A Product water output & $75 \mathrm{~m}^{3} / \mathrm{h}$ \\
& B Product quality & $550 \mathrm{ppm} \mathrm{TDS}$ \\
2 & A Sea water required & $214.3 \mathrm{~m} / \mathrm{h}$ \\
& B Sea water TDS & $35,000 \mathrm{ppm}$ \\
3 & \% Recovery & $35 \%$ \\
4 & Membrane element & $8040-\mathrm{HSY}-\mathrm{SWC1}$ \\
5 & Design flux & $4001 \mathrm{~m}^{-2} \mathrm{~d}^{-1}$ \\
6 & Average salt rejection & $98.5 \%$ \\
7 & Operating pressure & $52 \mathrm{~kg} / \mathrm{cm}^{2}$ \\
8 & Operating temperature & $236-38^{\circ} \mathrm{C}$ \\
9 & Energy consumption & $4.5 \mathrm{~kW} \mathrm{~h} / \mathrm{m}^{3}$ \\
\hline
\end{tabular}

The return stream of cooling seawater from the reject stages of the MSF plant is blended with the seawater to bring down the temperature to $36-38^{\circ} \mathrm{C}$ before the same is sent to the pre-treatment section of RO. The pre-treatment is conventional at present. The seawater is pumped through the clarifier and pressure sand filter. It is then passed through the cartridge filter to remove the particles up to $5 \mu \mathrm{m}$ size. Since the membranes are polyamide, dechlorination of seawater is carried out by adding $\mathrm{NaHSO}_{3}$. Acid dosing is given to minimize carbonate scaling followed by the addition of antiscalant or SHMP. The pretreated seawater is pumped into two parallel streams through the modules at a rate of $110 \mathrm{~m}^{3} / \mathrm{h}$ each. Pumps are fitted with an energy recovery hydraulic turbocharger. The seawater membrane element is 8040 spiral polyamide TFC with $400 \mathrm{lmd}$ flux and $98.8 \%$ salt rejection. The specific energy requirement is around $4.5 \mathrm{~kW} \mathrm{~h} / \mathrm{m}^{3}$ of water produced.

\section{Lab studies on preheat RO, integrated system and combined post-treatment [4]}

\subsection{Studies on elevated temperature $R O$ with various spiral elements}

The performance data of $100 \mathrm{~m}^{3} / \mathrm{d}$ SWRO pilot plant at Trombay during various seasons with seawater feed temperature ranging between $32^{\circ} \mathrm{C}$ and $36^{\circ} \mathrm{C}$ indicated a proportional increase in the product output and its salinity similar to that reported in literature. A detailed study was then carried out in a test loop to see the performance dependence on the temperature of various commercial spiral seawater elements. The results are plotted in Figures $3 \mathrm{a}$ and $3 \mathrm{~b}$, Table 3 . It is observed that the product output increase by $1.5-2.5 \%$ per degree rise for Filmtec and Koch (Fluid) system. The Hydranautic membranes show an increase of $1-1.5 \%$. The latter membrane also shows relatively higher salt rejection and correspondingly lower product output. The salt rejection in all the cases shows little change. The product quality remains below $500 \mathrm{ppm}$. It is therefore possible to use any of the commercial membranes for the preheat RO system. Further studies are continuing on this aspect. The NDDP, Kalpakkam uses Filmtec membranes.

\subsection{Studies on $N F / U F$ pretreatment (integrated system)}

The possible adoption of ultrafiltration (UF) and nanofiltration (NF) is envisaged to improve the hybrid plant performance further $\mathrm{RO}$ requires elaborate feed treatment for 
Figure 3 Variation of (a) solute rejection and (b) water flux with temperature for commercial seawater membranes

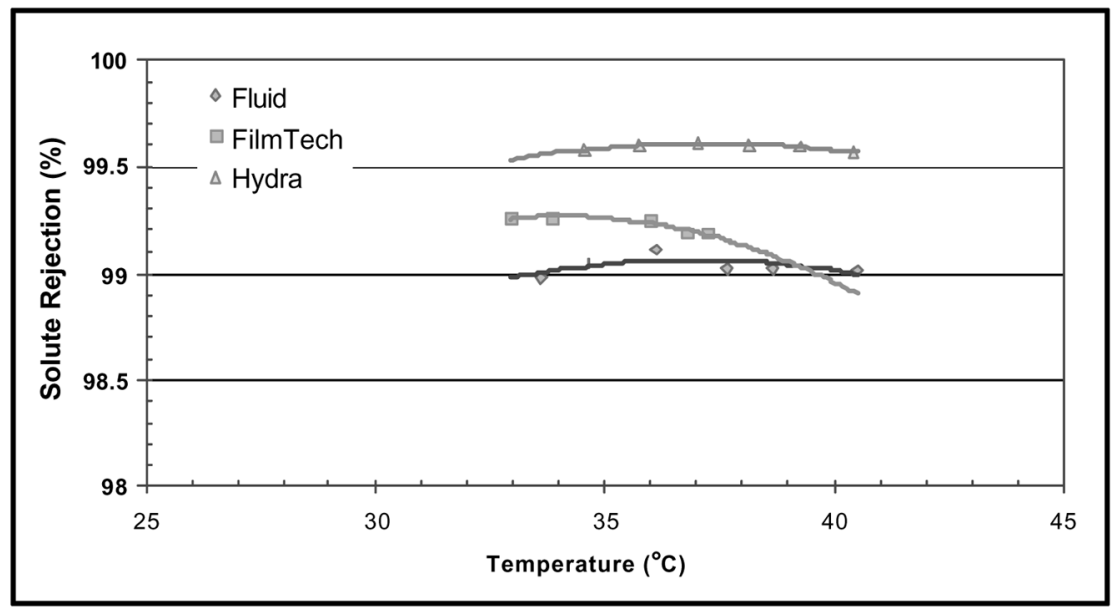

(a)

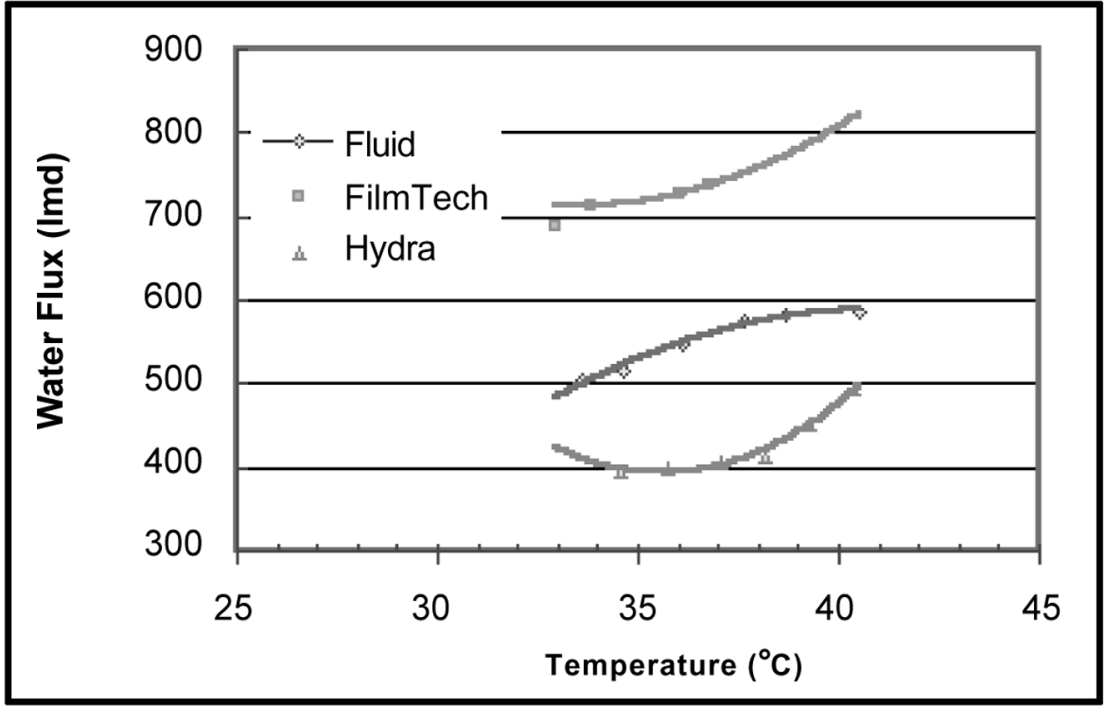

(b)

removal of scaling constituents, suspended impurities, organics and microbial load. The UF installed upstream of RO can be effectively used for the pretreatment. The UF membrane systems eliminate the requirement for clariflocculators, pressure sand filters, activated carbon filters and cartridge filters. A $50 \mu \mathrm{m}$ SS strainer is, however, used for removal of large debris. The need for chlorination is also obviated as the UF membranes remove all the microorganisms, which tend to foul the RO membrane. With low turbidity of raw water, the membrane life of UF treated water is reported to increase to at least five years. 
Preliminary investigations have been carried out by using NF as a means to improve the performance of an MSF-RO hybrid desalination plant. NF reduces the hardness ions of calcium, magnesium and sulphate to a great extent. It also partially reduces the TDS of seawater. An NF-MSF-RO appears to have good potential leading to higher top brine temperature offering higher GOR for MSF and significantly improving the product output due to increased recovery in RO. The data from our pilot plants on UF/NF treatment are given in Table 5.

Table 5 Role of NF/UF in pretreatment of seawater

\begin{tabular}{lcc}
\hline & Pre & Post \\
\hline$N F$ pretreatment of seawater & & \\
$\quad$ Constituents (ppm) & 38,000 & 30,000 \\
TDS & 6,000 & 1,000 \\
Hardness & 400 & 40 \\
Calcium & 2,400 & 200 \\
Sulphate & 150 & 50 \\
Alkalinity & & $<1$ \\
UF pretreatment of seawater & 50 & $90 \%$ removal \\
Turbidity, NTU & 6,000 & By a factor of 104 \\
Organics & - & \\
Microorganism
\end{tabular}

\subsection{Combined post treatment of product water}

The post-treatment of product water from both MSF and RO plants is desire from the point of view of providing end-use quality as well as for the preservation of distribution systems. The blending of the two streams from MSF and RO plants eliminates some of the post-treatments which is done in the case of a single desalination plant. Based on the desired product water quality from both the MSF and RO plants in our hybrid system, a simple flow sheet has been prepared which indicates cost savings compared to a single plant. This consists of monitoring the $\mathrm{pH}$, TDS and LSF of individual product streams and blending them in the ratio of 1 (RO): 2 (MSF). Various doses of lime were added into the combined product to achieve a combined product of less than $200 \mathrm{ppm}$ and LSI ranging from -0.1 to +0.13 . This LSI is adequate for storage and distribution through a CI pipeline (Table 6).

Table 6 Combined post treatment study at Trombay (product for $425 \mathrm{~m}^{3} / \mathrm{d}$ MSF and $100 \mathrm{~m}^{3} / \mathrm{d}$ SWRO plant)

\begin{tabular}{|c|c|c|c|c|c|c|c|}
\hline \multirow{2}{*}{$\begin{array}{l}\text { Milk of lime } \\
\text { Dose rate }(\mathrm{lpm})\end{array}$} & \multicolumn{2}{|c|}{ MSF plant } & \multicolumn{2}{|c|}{ RO plant } & \multicolumn{3}{|c|}{ Combined product } \\
\hline & $T D S$ & $p H$ & $T D S$ & $p H$ & $T D S$ & $p H$ & $L S I$ \\
\hline 0.8 & 20 & 7.2 & 510 & 5.9 & 180 & 7.4 & -0.01 to +0.13 \\
\hline 1.0 & 20 & 7.2 & 530 & 5.9 & 190 & 7.5 & \\
\hline 1.3 & 30 & 7.2 & 510 & 5.7 & 200 & 7.5 & \\
\hline 1.4 & 30 & 6.9 & 550 & 6.3 & 200 & 7.5 & \\
\hline 1.5 & 20 & 6.9 & 510 & 6.3 & 200 & 7.5 & \\
\hline 2.0 & 30 & 7.3 & 540 & 6.0 & 230 & 9.3 & \\
\hline
\end{tabular}




\section{Moderator waste heat from nuclear reactor for desalination [5]}

About 40 and $100 \mathrm{MWth}$ low temperature waste heat is available in the moderator systems of the 220 and 500 MWe PHWRs respectively. A significant part of this waste heat can be utilized for seawater desalination for in-house consumption.

The Low Temperature Evaporation (LTE) technology for producing water from seawater has been demonstrated at $30 \mathrm{~m}^{3} / \mathrm{d}$ scale by using the low temperature waste heat at BARC. This plant is being connected to the CIRUS reactor to demonstrate coupling to a research reactor. The flowsheet of the scheme is shown in Figure 4. Some of the attractive features of the LTE technology are (i) use of chemicals is minimal in feed water treatment, (ii) reduces thermal pollution.

Figure 4 Schematic diagram of the LTE desalination plant coupled to nuclear reactor (CIRUS)

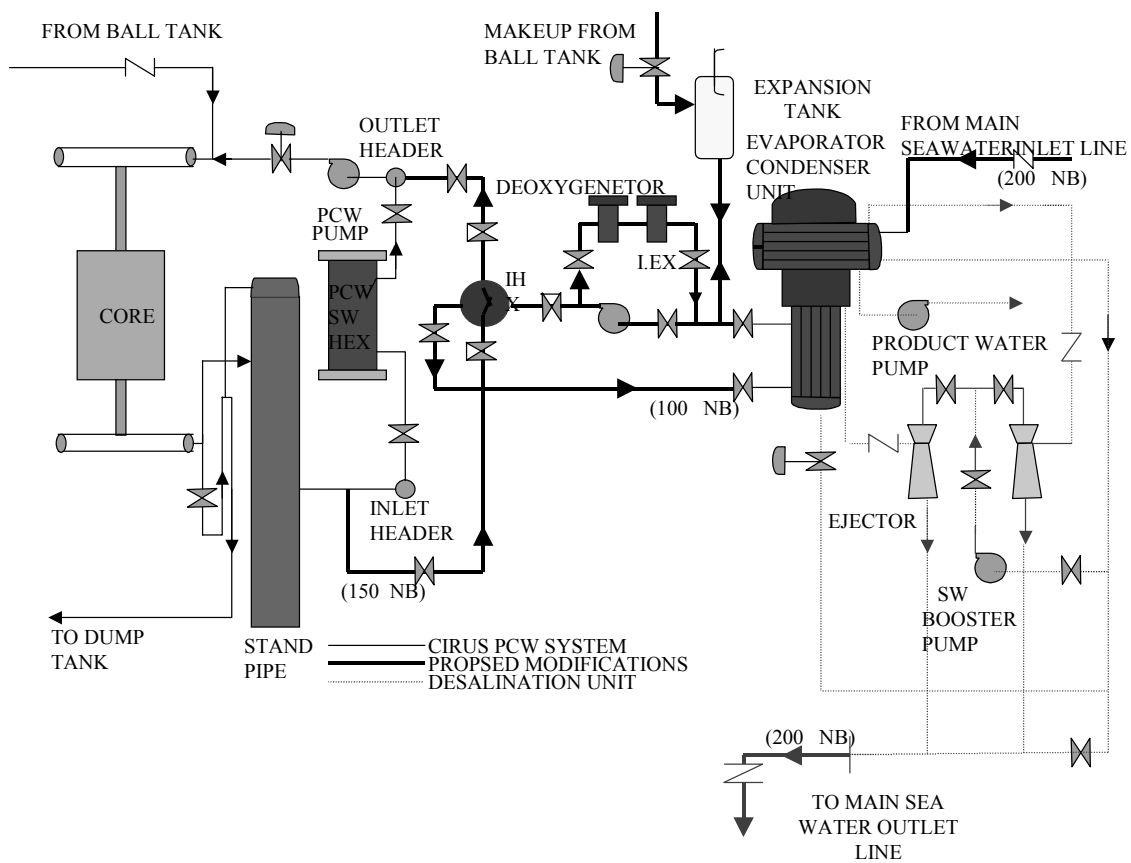

The dependence of hot water temperature on the product output and quality for the LTE plant was studied and the data are presented in Table 7. It clearly shows a reduced output with lower hot water temperature, however, without affecting the product water quality. Studies are being conducted worldwide on the use of waste heat to generate motive steam for utilization in HTTF evaporators for seawater desalination. Such studies will be of immense benefit for cost effectiveness of desalted water. 
Table 7 Output of LTE desalination plant at various hot water temperatures

\begin{tabular}{|c|c|c|c|c|}
\hline \multirow[b]{2}{*}{ S. No. } & \multirow{2}{*}{$\begin{array}{c}\text { Hot water temperature } \\
\left({ }^{\circ} \mathrm{C}\right)\end{array}$} & \multicolumn{2}{|c|}{ Product water flow rate } & \multirow{2}{*}{$\begin{array}{l}\text { Total dissolved solids in the } \\
\text { product water (ppm) }\end{array}$} \\
\hline & & lpm & $\mathrm{Te} / \mathrm{d}$ & \\
\hline 1 & 50 & 7.0 & 10.0 & 5 \\
\hline 2 & 55 & 10.5 & 15.1 & 4.5 \\
\hline 3 & 60 & 15.0 & 21.6 & 5.5 \\
\hline 4 & 62 & 17.0 & 24.5 & 4 \\
\hline 5 & 65 & 21.0 & 30.2 & 5 \\
\hline
\end{tabular}

Hot water flow rate: $1600 \mathrm{lpm}$.

Vacuum in the evaporator: $700 \mathrm{~mm} \mathrm{Hg}$.

Evaporation temperature: $41^{\circ} \mathrm{C}$.

Seawater concentration: $33,500 \mathrm{ppm}$.

\section{Conclusion}

The design of the hybrid MSF-RO plant to be set up at an existing nuclear power station has been presented. The MSF plant based on long tube design requires less energy. The effect on performance of the MSF plant due to higher seawater intake temperature is marginal. The preheat RO system part of the hybrid plant uses reject cooling seawater from the MSF plant. This allows a lower pressure operation, resulting in energy saving. The two qualities of water produced are usable for the power station as well as for drinking purposes with appropriate blending. The post-treatment is also simplified due to blending of the products from MSF and RO plants. Adoption of UF at a future date appears desirable to extend the membrane life of the RO plant. The LTE desalination plant can be operated using the moderator waste heat from a research reactor. The product water from this plant can meet the make up water requirement of the reactor after minor polishing.

\section{References}

1 Misra, B.M. and Konishi, T. (2001) 'Freshwater from the seas', IAEA Bulletin, Vol. 43, No. 2, pp. 5-8.

2 Adak, A.K., Tewari, P.K., Verma, R.K. and Misra, B.M. (2001) 'Design considerations of coupling multi-stage flash (MSF) desalination plant of NDDP with MAPS', BARC/2001/I/003.

3 Misra, B.M. and Sadhukhan, H.K. (1997) 'National programmes and activities on nuclear desalination in India', IAEA Symposium on Desalination, Taejon, IAEA-SM-347/7.

4 Tewari, P.K., Misra, B.M. and Bhattacharjee, B. (2002) 'Design details of a hybrid MSF-RO desalination plant', IDA Conference, Manama, Bahrain.

5 Tewari, P.K., Verma, R.K., Misra, B.M. and Sadhukhan, H.K. (1997) 'Low temperature vacuum evaporation process for sea water desalination using waste heat of PHWRs', IAEA Symposium on Desalination, Taejon, IAEA-SM-347/34. 